\title{
Drug utilization pattern of antimicrobial agents in an outpatient department of otorhinolaryngology in a tertiary care hospital: a prospective, cross-sectional study
}

\begin{abstract}
Sanket B. Sathiya ${ }^{1}$, Ashwin K. Panchasara ${ }^{2}$, Manish J. Barvaliya ${ }^{1}$, Sushil G. Jha ${ }^{1}$, C. B. Tripathi ${ }^{1}$

${ }^{1}$ Department of Pharmacology, Government Medical College, Bhavnagar, Gujarat, India, ${ }^{2}$ Department of Pharmacology, GMERS Medical College, Sola, Ahmedabad, Gujarat, India

Received: 20 December 2015 Accepted: 7 January 2016

*Correspondence to:

Dr. Ashwin K. Panchasara, Email: ashwin_panchasara@ yahoo.com

Copyright: () the author(s), publisher and licensee Medip Academy. This is an openaccess article distributed under the terms of the Creative Commons Attribution NonCommercial License, which permits unrestricted noncommercial use, distribution, and reproduction in any

ABSTRACT

Background: Study based on antimicrobial drug utilization pattern and focus on factors related to prescribing, administering and its associated events. The aim of this study is to assess the prescribing patterns of antimicrobials, to assess the appropriateness of prescribed antimicrobials in an ear, nose and throat (ENT) infections.

Methods: A prospective observational drug utilization study was carried out in otorhinolaryngology department for a period of 4 months. Patients who attended the ENT outpatient department (OPD) with ENT infections were included in the study and patients who were not willing to participate in the study were excluded and the data were analyzed.

Results: Out of 155 patients, the average number of drugs per patient was 1.2. The percentage of drugs prescribed with the generic name was $26.32 \%$. During this study, it was found that the most commonly prescribed groups of antimicrobials were penicillins $(34.87 \%)$ followed by fluroqinolones $(26.32 \%)$ and nitroimidazole (25\%). During the study, it was observed that $46.71 \%$ patients visited for treating ear infections, $12.5 \%$ for nasal infections and $40.79 \%$ for throat infections. The routes of administration were oral $(74.23 \%)$ and topical $(20.10 \%)$.

Conclusions: Our study shows some rational prescription patterns like less utilization of antimicrobials in ENT infections and were according to standard treatment guideline. The results of this study will be useful in future for making standard treatment guidelines. It also promotes the rational prescription and rational use of drugs.
\end{abstract} medium, provided the original work is properly cited.
Keywords: Drug utilization, Antimicrobial agent, ENT infections, WHO indicators, Prescribing pattern

\section{INTRODUCTION}

The routine life of children and adults are disturbed by diseases of ear, nose and throat (ENT) and also cause significant morbidity. ${ }^{1}$ Infections remain the major cause of ENT diseases because of increase in the population. Among all the infections of ENT, upper respiratory tract infections (URTIs) are very common. The respiratory tract infections were found the fourth major cause of mortality according to World Health Report of 2004 estimated by the World Health Organization (WHO). In 2002, 6.9\% deaths and 94.6 disability adjusted life years (DALY) were lost globally because of respiratory tract infections. ${ }^{2}$ Hospital admissions are common because of acute respiratory tract infections which includes approximately $20-40 \%$ of outpatient and $12-35 \%$ of inpatient. URTIs include naso-pharyngitis, otitis media, tonsillitis and pharyngitis which account for $87.5 \%$ of respiratory tract infections and are responsible for the hearing loss and absenteeism from work. ${ }^{3}$

The acute URTIs are mainly caused by viruses in most cases and resolve spontaneously, hence antimicrobial agents are not necessary until it is complicated and severe. $^{3}$ The different studies found that antimicrobials were prescribed in almost $90 \%$ cases of pharyngitis. The resistant of antimicrobials is very prominent in the various part of Asia. Resistance is found common against penicillin, nalidixiac acid and chloramphenicol among people of India. ${ }^{4}$ The lack of compliance to the 
medications is also important and it is associated with deterioration of patient's health, extra medicines, additional costs and hospital admission. ${ }^{5}$

Even though antimicrobials are used since many years, little is known about how antimicrobials should be used. The important question is how it should be prescribed to minimize the resistant without altering the efficacy and safety. International network for the rational use of drugs (INRUD) was started to increase the rational use of the drugs. The WHO and INRUD had developed indicators for the evaluation of drug use. ${ }^{6}$ Evaluation of drug utilization is a continuous and systemic process which is designed to review the prescribing patterns, develop standard treatment guideline develop criteria for rational use of drugs and promote appropriate drug use. There are very less information about antimicrobial use. So, it is necessary to look for the pattern of drug utilization by the time and to make necessary modification in prescription to increase efficacy and decrease the adverse effects. ${ }^{7}$ With the aim of that, the present study was carried out to evaluate drug utilization pattern of antimicrobials among patients of ENT infections in outpatient (OPD) department at Sir Takhtasinhji General Hospital attached to Government Medical College, Bhavnagar, Gujarat, India.

\section{METHODS}

Ethical approval was obtained from the institutional review board (IRB), Government Medical College, Bhavnagar, Gujarat, India. Patients were thoroughly informed about the study and written informed consent was taken before their enrolment into the study. This was a prospective and cross sectional study. The study was held at the otorhinolaryngology OPD of Sir Takhtasinhji general hospital attached to government medical college, Bhavnagar, Gujarat, India from November 2013 to February 2014. It was based on antimicrobial agents prescribed in ear, nose \& throat infections. All the patients who were taking antimicrobial agents were included into the study. The pregnant and lactating mothers were also enrolled into the study. The patients who were not taking antimicrobial agents and those were not able to give consent were excluded. Those patients who did not want to participate into the study were also excluded from the study. All the information was recorded in case record form (CRF) which was designed according to WHO criteria. It includes age, gender, other details of patient, investigations, information related with prescription drug information from the prescriber like the indication, dose, frequency of drug administration, routes of administration, duration of therapy and concomitant disease / condition.

\section{Outcome measures}

The WHO/INRUD indicators were followed in the present study in addition to other indicators. Types of infections, types of antimicrobial used, commonly prescribed agents, number of antimicrobials per prescription, antimicrobial agents used as a single drug, fixed dose combination therapy and multiple drug therapy, number of antimicrobials prescribed by generic and brand name.

\section{Statistical analysis}

Data were expressed in percentage and descriptive statistics were used.

\section{RESULTS}

A total of 152 patients were selected for the study over a period of 4 months. Among 152 patients, 79 (51.98\%) were male and $73(48.02 \%)$ were female. The maximum numbers of patients were found in the 19-60 years of age group (adult) while the lowest number was in $>60$ years (geriatric) of age group (Table 1).

Table 1: Baseline demographics of ENT patients.

\begin{tabular}{|ll|}
\hline Demographics of ENT patients \\
\hline Age & No. $(\%)$ \\
\hline Pediatric (<18 years) & $37(24.34 \%)$ \\
\hline Adult (19 to 60 years) & $103(67.76 \%)$ \\
\hline Geriatrics (>60 years) & $12(7.89 \%)$ \\
\hline Gender & No. $(\%)$ \\
\hline Male & $79(51.97 \%)$ \\
\hline Female & $73(48.02 \%)$ \\
\hline Religion & No. $(\%)$ \\
\hline Hindu & $125(82.23 \%)$ \\
\hline Muslim & $27(17.76 \%)$ \\
\hline Domicile & No. $(\%)$ \\
\hline Rural & $59(38.81 \%)$ \\
\hline Urban & $93(61.18 \%)$ \\
\hline Socioeconomic status & No. $(\%)$ \\
\hline Low & $90(59.21 \%)$ \\
\hline Medium & $60(39.47 \%)$ \\
\hline High & $02(1.31 \%)$ \\
\hline
\end{tabular}

The most commonly prescribed groups of antimicrobials in this study were penicillins $(34.87 \%)$ followed by fluroqinolones $(26.32 \%)$ and nitroimidazole $(25 \%)$ (Table 2). The most commonly prescribed agent of these classes was amoxicillin, amoxicillin with clavulanic acid $(34.2 \%)$, metronidazole $(25 \%)$ and ciprofloxacin (22.37\%) (Table 2). The most commonly prescribed antimicrobials were amoxicillin (29.58\%), ciprofloxacin $(23.94 \%)$ and doxycycline $(23.94 \%)$ in ear infection; amoxicillin (36.84\%), ciprofloxacin (42.10\%) and metronidazole $(31.58 \%)$ in nose infection; amoxicillin $(37.1 \%)$, metronidazole $(35.48 \%)$ and azithromycin $(16.13 \%)$ in throat infections.

Most commonly prescribed antimicrobials were amoxicillin $(48.65 \%)$ and metronidazole $(32.43 \%)$ in pediatric patients; amoxicillin $(28.16 \%)$ and ciprofloxacin $(25.24 \%)$ in adult patients; metronidazole $(33.33 \%)$ and amoxicillin $(25 \%)$ in geriatric patients. In male patients, 
Table 2: Most commonly used anti-microbial agents in ear, nose and throat infections.

\begin{tabular}{|c|c|c|c|c|}
\hline Drug & $\operatorname{Ear} \mathbf{N}=71$ & Nose $\mathbf{N}=19$ & Throat $N=62$ & Total $N=152$ \\
\hline \multicolumn{5}{|l|}{ Penicillins 53 (34.87\%) } \\
\hline Amoxicilin & $21(41.17 \%)$ & $07(13.73 \%)$ & $23(45.1 \%)$ & $51(33.55 \%)$ \\
\hline Co-amoxiclav & 00 & 00 & $01(100 \%)$ & $01(0.65 \%)$ \\
\hline Ampicillin + Cloxacillin & 00 & 00 & $01(100 \%)$ & $01(0.65 \%)$ \\
\hline \multicolumn{5}{|l|}{ Fluroqinolones 40 (26.32\%) } \\
\hline Ciprofloxacin & $17(50 \%)$ & $08(23.53 \%)$ & $09(26.47 \%)$ & $34(22.37 \%)$ \\
\hline Norfloxacin & $01(100 \%)$ & 00 & 00 & $01(0.65 \%)$ \\
\hline Levofloxacin & 00 & $01(20 \%)$ & $04(80 \%)$ & $05(3.29 \%)$ \\
\hline \multicolumn{5}{|l|}{ Nitroimidazoles 38 (25\%) } \\
\hline Metronidazole & $10(26.32 \%)$ & $06(15.79 \%)$ & $22(57.9 \%)$ & $38(25 \%)$ \\
\hline \multicolumn{5}{|l|}{ Tetracyclines $29(19.07 \%)$} \\
\hline Doxycycline & $17(58.62 \%)$ & $02(6.9 \%)$ & $10(34.48 \%)$ & $29(19.07 \%)$ \\
\hline \multicolumn{5}{|l|}{ Macrolides $13(8.55 \%)$} \\
\hline Azithromicin & $01(9.09 \%)$ & 00 & $10(90.9 \%)$ & $11(7.24 \%)$ \\
\hline Erythromycin & 00 & 00 & $02(100 \%)$ & $02(1.31 \%)$ \\
\hline \multicolumn{5}{|l|}{ Cephalosporins $11(7.24 \%)$} \\
\hline Cefaclor & $02(100 \%)$ & 00 & 00 & $02(1.32 \%)$ \\
\hline Cefixime & $01(33.33 \%)$ & $01(33.33 \%)$ & $01(33.33 \%)$ & $03(1.97 \%)$ \\
\hline Cefotaxime & $02(66.66 \%)$ & 00 & $01(33.33 \%)$ & $03(1.97 \%)$ \\
\hline Cefadroxil & $04(100 \%)$ & 00 & 00 & $04(2.63 \%)$ \\
\hline \multicolumn{5}{|l|}{ Aminoglycosides 3 (1.97\%) } \\
\hline Gentamicin & 00 & 00 & $01(100 \%)$ & $01(0.65 \%)$ \\
\hline Neomicin & $01(50 \%)$ & $01(50 \%)$ & 00 & $02(1.32 \%)$ \\
\hline \multicolumn{5}{|l|}{ Antifungals $2(1.32 \%)$} \\
\hline Clotrimazole & $02(100 \%)$ & 00 & 00 & $02(1.32 \%)$ \\
\hline $\begin{array}{l}\text { Chloramphenicol/Beclomethasone } \\
\text { Dipropionate/Clotrimazole/Lignocaine }\end{array}$ & $03(100 \%)$ & 00 & 00 & $03(1.97 \%)$ \\
\hline Chloramphenicol & $02(100 \%)$ & 00 & 00 & $02(1.32 \%)$ \\
\hline
\end{tabular}

Table 3: Most commonly found infections and antimicrobial agents in different age groups.

\begin{tabular}{|c|c|c|}
\hline & Diseases (\%) & Drugs (\%) \\
\hline Pediatrics & $\begin{array}{l}\text { Tonsillitis }(32.43 \%) \\
\text { CSOM }(24.32 \%) \\
\text { ASOM }(10.81 \%)\end{array}$ & $\begin{array}{l}\text { Amoxicillin }(48.65 \%) \\
\text { Metronidazole }(32.43 \%) \\
\text { Ciprofloxacin }(13.51 \%) \\
\text { Doxycycline }(10.81 \%)\end{array}$ \\
\hline Adult & $\begin{array}{l}\text { CSOM (37.86\%) } \\
\text { Pharyngitis }(22.33 \%) \\
\text { Tonsillitis }(15.53 \%) \\
\text { Nasal vestibulitis }(5.83 \%) \\
\text { ASOM }(4.85 \%)\end{array}$ & $\begin{array}{l}\text { Amoxicillin }(28.16 \%) \\
\text { Ciprofloxacin }(25.24 \%) \\
\text { Doxycycline }(22.33 \%) \\
\text { Metronidazole }(17.48 \%)\end{array}$ \\
\hline Giriatrics & $\begin{array}{l}\text { CSOM }(33.33 \%) \\
\text { Nasal vestibulitis }(16.66 \%)\end{array}$ & $\begin{array}{l}\text { Metronidazole }(33.33 \%) \\
\text { Amoxicillin }(25 \%) \\
\text { Ciprofloxacin }(25 \%)\end{array}$ \\
\hline Male & $\begin{array}{l}\text { CSOM }(30.38 \%) \\
\text { Pharyngitis }(21.52 \%) \\
\text { Tonsillitis }(21.52 \%) \\
\text { Nasal vestibulitis }(6.32 \%) \\
\text { ASOM }(5.06 \%)\end{array}$ & $\begin{array}{l}\text { Amoxicillin }(34.17 \%) \\
\text { Metronidazole }(25.32 \%) \\
\text { Doxycycline }(16.46 \%) \\
\text { Ciprofloxacin }(16.46 \%)\end{array}$ \\
\hline Female & $\begin{array}{l}\text { CSOM }(38.36 \%) \\
\text { Tonsillitis }(16.44 \%) \\
\text { Pharyngitis }(13.70 \%) \\
\text { ASOM }(6.85 \%)\end{array}$ & $\begin{array}{l}\text { Amoxicillin }(32.87 \%) \\
\text { Ciprofloxacin }(31.51 \%) \\
\text { Doxycycline }(21.92 \%) \\
\text { Metronidazole }(17.80 \%)\end{array}$ \\
\hline
\end{tabular}


most commonly prescribed antimicrobials were amoxicillin (34.17\%), metronidazole $(25.32 \%)$ and in female patients, they were amoxicillin (32.87\%) and ciprofloxacin $(31.51 \%)$ (Table 3$)$.

The ear, nose and throat infections were found in $46.71 \%$, $12.5 \%$ and $40.79 \%$ of patients during this study (Table 4 ). Among these, most commonly found infections were tonsillitis $(32.43 \%)$ and chronic suppurative otitis media (CSOM) (24.32\%) in paediatric patients; CSOM $(37.86 \%)$ and pharyngitis $(22.33 \%)$ in adult patients; CSOM $(33.33 \%)$ and nasal vestibulitis $(16.66 \%)$ in geriatric patients. In males, most commonly found infections were CSOM $(30.38 \%)$ and pharyngitis (21.52\%) while in female they were CSOM (38.36\%) and tonsillitis $(16.44 \%)$. The most frequent associated conditions of the study population were hypertension $(7.89 \%)$, diabetes $(2.63 \%)$ and tuberculosis $(0.65 \%)$ (Table 5).

\section{Table 4: Most commonly found ear, nose and throat} infections.

\begin{tabular}{|lll|}
\hline Infections & Diseases & No. (\%) \\
\hline Ear & C.S.O.M. & $52(34.21 \%)$ \\
\hline & A.S.O.M. & $09(5.92 \%)$ \\
\hline & Otto mycosis & $04(2.63 \%)$ \\
\hline & C.S.O.M. + Cholesteatoma & $03(1.97 \%)$ \\
\hline & Ottitis Externa & $02(1.32 \%)$ \\
\hline & Fungal Ottitis media & $01(0.66 \%)$ \\
\hline Total & $\mathbf{7 1}(\mathbf{4 6 . 7 1 \%})$ \\
\hline & Nasal Vestibulitis & $09(5.92 \%)$ \\
\hline & Allergic Rhinitis + D.N.S. & $05(3.29 \%)$ \\
\hline & Maxillary Sinusitis & $03(1.97 \%)$ \\
\hline Dacrocystitis & $02(1.32 \%)$ \\
\hline Throat & Total & $\mathbf{1 9}(\mathbf{1 2 . 5 \%})$ \\
\hline & Pharyngitis & $27(17.76 \%)$ \\
\hline & Tonsilitis & $27(17.76 \%)$ \\
\hline & Parotitis & $04(2.63 \%)$ \\
\hline & Peritonsilar abccess & $01(0.66 \%)$ \\
\hline Acute Epiglotitis & $01(0.66 \%)$ \\
\hline Cervical Abccess & $01(0.66 \%)$ \\
\hline Submendibular Abscess & $01(0.66 \%)$ \\
\hline Total & $\mathbf{6 2}(\mathbf{4 0 . 7 9 \% )}$ \\
\hline
\end{tabular}

A total no. of antimicrobials prescribed was 194. Their routes of administration were oral $(74.23 \%)$ and topical (20.10\%). The mean number of antimicrobial drugs prescribed per patient was 1.2. Culture sensitivity tests were not performed in any of the patient out of 152 . The antimicrobial agents prescribed by their generic names were seen in only $26.32 \%$ patients while rests of the prescriptions were by their brand names. In this study, it was observed that a total of $77.63 \%$ patients received antimicrobial monotherapy, whereas $22.37 \%$ patients received multiple drug therapy. From 152 patients, 12 patients had taken self-medications among them 3 patients had taken Ayurvedic medication, 6 patients had taken homeopathic medications and 3 patients had taken other medication.

Table 5: Concomitant disease conditions associated with ENT infections.

\begin{tabular}{|ll|}
\hline Concomitant condition & No. of patients $(\%)$ \\
\hline Hypertension & $12(7.89 \%)$ \\
\hline Diabetes mellitus & $4(2.63 \%)$ \\
\hline Tuberculosis & $1(0.65 \%)$ \\
\hline Gastritis & $1(0.65 \%)$ \\
\hline Total & $18(11.84 \%)$ \\
\hline
\end{tabular}

\section{DISCUSSION}

Prescription by the doctors shows attitude of the doctors towards the patients and diseases. There is much variation in prescription of antimicrobials. Irrational and indiscriminate use of the antimicrobials for the treatment of infections may increase the bacterial resistance. ${ }^{8}$ In the present study, prescriptions for male were $52 \%$ as compared to females which may be because of males are more travelling. This result is similar with other studies conducted by MR Ain et al, Pradhan et al, Yadav Pramila et al and Shankar et al. ${ }^{9-12}$ However, in some other study it was shown that ENT infections were common in females as compared to males which might be because of their exposure to kitchen smoke in the Indian context. ${ }^{13}$ Most of the patients in our study were from metropolitan backgrounds which contradict to the other study conducted by Khan et al. It may be because of selfmedications of antimicrobials by urban population. ${ }^{14}$

Our study shows that ear infections (46.71\%) were common, followed by throat $(40.79 \%)$ while nose infections $(12.5 \%)$ were least common. This is in accordance with other study conducted by Yadav Pramila et al who also shows ear infections (50.8\%) were common, followed by throat $(31.37 \%)$ and nose infections (26.47\%) were less common. ${ }^{11}$ Among ontological diseases, CSOM was the most commonly found condition which may be due to ignorance about the disease and inadequate medical management at the peripheral level. In present study, most commonly prescribed antimicrobials were penicillin (34.87\%), followed by fluroqinolones $(26.32 \%)$ and nitroimidazole (25\%). The most commonly prescribed antimicrobial agents were amoxicillin (33.55\%), ciprofloxacin $(22.37 \%)$ followed by metronidazole (25\%). This contradicts to other study conducted by Das et al who shows ciprofloxacin $(23.85 \%)$ was the most commonly prescribed agent followed by amoxicillin (20.06\%), a combination of ampicillin + cloxacillin (9.17\%), doxycycline $(5.96 \%)$, erythromycin $(4.58 \%)$ and cotrimoxazole $(4.58 \%) .{ }^{14}$ The use of broad spectrum antimicrobials like ampicillin and amoxicillin + clavulanic acid as found in our study might be because of increase in antimicrobial resistance which stimulates the surgeons to prescribe broad spectrum and safer antibiotics. In our study, amoxicillin was most commonly 
prescribed antimicrobial which may be because of preponderant mixed bacterial infections. The result of the present study is similar to the other study done by MR Ain et al in which amoxicillin was the most common prescribed antimicrobial. ${ }^{10}$ Majority of the antimicrobial were prescribed on the basis of clinical experience of the ENT surgeons but it is advisable to go for culture sensitivity before prescribing antimicrobials.

The average number of antimicrobial agents prescribed per patient was 1.2 which was similar to other study by Das et al. in which 1.4 antimicrobial agents were prescribed per patient. ${ }^{15}$ Rationality of the prescription is determined by average number of drugs per prescription. Hence, ENT surgeons should prescribe minimum number of drugs per prescription which reduces bacterial resistance, cost of therapy and drug interaction. ${ }^{8,16}$ Further, in our study $77.63 \%$ patients received single antimicrobial drug whereas $22.36 \%$ patients received multi drug therapy which was similar with other study. ${ }^{9,10}$ The routes of administration of antimicrobials used in this study according to standard treatment guideline. The major numbers of prescriptions were by their brand names which may be because of drug promotional activities by pharmaceutical industries. Numbers of prescriptions with drugs by generic names were less. ${ }^{17}$ Prescribing the antimicrobial agents by brand names may affect some of the features of essential drug concept. The overall health expenditure can be reduced by prescribing the drugs by generic names. However, in spite of all these limitations, our study shows few rational prescribing practices. Prescription of antimicrobials in ear, nose and throat infections were according to standard treatment guideline. Continuous motivation, education and monitoring are needed at different levels to encourage rational use of medicines.

\section{CONCLUSION}

Present study shows some rational practice like less use of antimicrobials in ENT infections and was according to standard treatment guideline. Prescriptions by brand names, prescription of broad spectrum antimicrobial without culture and sensitivity reports are some irrational practices. The results of this study will be useful in future for making and improving standard treatment guidelines. It also promotes the rational prescription and rational use of medicines.

Funding: No funding sources

Conflict of interest: None declared

Ethical approval: The study was approved by the Institutional Ethics Committee

\section{REFERENCES}

1. Grace NN, Bussmann RW. Traditional management of ear, nose and throat (ENT) diseases in Central Kenya. J Ethnobiol Ethnomed. 2006;2:54.
2. Burden of illness and management options. Geneva, Switzerland: World Health Organization;2004.

3. Jain N, Lodha R, Kabra SK. Upper respiratory tract infections. Indian J Pediatr. 2001;68:1135-8.

4. Huovinen P. Magic bullets, lost horizons: the rise and fall of antibiotics. BMJ. 2002;324(7330):176.

5. Kardas P. Patient compliance with antibiotic treatment for respiratory tract infections. J Antimicrob Chemother. 2002;49(6):897-903.

6. Laporte JR, Porta M, Capella D. Drug utilization studies: A tool for determining the effectiveness of drug use. Br J Clin Pharmacol. 1983;16:301-4.

7. Krishnaswamy K, Kumar BD, Radhaiah G. A drug delivery percept and practices. Eur J Clin Pharmacol. 1985;29:363-70.

8. Stille CJ, Andrade SE, Huang SS, Nordin J, Raebel MA, Go AS et al. Increased use of second-generation macrolide antibiotics for children in nine health plans in the United States. Paediatrics. 2004;114:1206-11.

9. Pradhan S, Jauhari AC. A study of antibiotics used in adult respiratory disorders in Kathmandu and Bhaktapur. Nepal Med Coll J. 2007;9:120-4.

10. Shankar PR, Upadhyay DK, Subish P, Dubey AK, Mishra P. Prescribing patterns among pediatric inpatients in a teaching hospital in western Nepal. Singapore Med J. 2006;47:261-5.

11. Yadav P, Kanase V, Lacchiramka P, Jain S. Drug utilization trends in ENT outpatient department in a Teaching hospital. Int J Pharma Bio Sci. 2010;1(4):15360.

12. MR Ain, Shahzad N, Aqil M, Alam MS, Khanam R. Drug utilization pattern of antibacterials used in ear, nose and throat outpatient and inpatient departments of a university hospital at New Delhi, India. J Pharm Bioallied Sci. 2010;2:8-12.

13. Dhingra PL. Diseases of ear, nose and throat. $3^{\text {rd }}$ ed. New Delhi: Mosby, Saunders, Elsevier;2004:62-117.

14. Khan FA, Nizamuddin S. Drug Utilization Patterns of antimicrobial agents in the outpatient department of ENT in a tertiary care teaching hospital of North India. JAPHR. 2011;1(2):22-30.

15. Das BP, Sethi A, Rauniar GP, Sharma SK. Antimicrobial utilization pattern in outpatient services of ENT department of tertiary care hospital of Eastern Nepal. Kathmandu Univ Med J. 2005;3:370-5.

16. Atanasova I, Terziivanov D. Investigations on antibiotics in a hospital for $1^{\text {st }}$ year period. Int $\mathrm{J}$ Clin Pharmacol Ther. 1995;33:32-3.

17. Till B, Williams L, Oliver SP, Pillans PI. A survey of inpatient antibiotic use in a teaching hospital. S Afr Med J. 1991;8:7-10.

Cite this article as: Sathiya SB, Panchasara AK, Barvaliya MJ, Jha SG, Tripathi CB. Drug utilization pattern of antimicrobial agents in an outpatient department of otorhinolaryngology in a tertiary care hospital: a prospective, cross-sectional study. Int J Basic Clin Pharmacol 2016;5:65-9. 